\title{
Brief Description of Business Model and Construction of Conceptual Model about Environmental Management Industry from the Perspective of Stakeholders
}

\author{
Yong Wang and Rongbing Hu
}

\begin{abstract}
Competition among enterprises is no longer the competition between products, but the competition between business models. Innovation in business models is a booster for the development of environmental management industry. The article starts with the literature of the business model of environmental management industry and analyzes the present research situation and characteristics. Then, the conceptual model of environmental management industry business model is constructed and its internal meaning is expounded from the perspective of stakeholders.
\end{abstract}

Index Terms-Business model, environmental management industry, stakeholder.

\section{ENVIRONMENT AND ENVIRONMENT MANAGEMENT}

Resource exhaustion, environmental pollution, and ecological damage have become a bottleneck of sustainable economic and social development, as well as a huge threat to human health. Environmental protection is one of the most urgent problems facing the Chinese government. Over the more than 30 years since the reform and opening-up, China has undergone rapid economic development and become the world's second largest economy. However, the contradiction between environment management and economic development is increasingly conspicuous. The government is now increasing investment in environmental protection. From 2009 to 2012 the investment in environmental protection amounted to 2.3 trillion yuan, among which 780 billion yuan was invested in environmental pollution control and facilities operating. It is necessary to increase investment but the more important thing is to ensure the source, input, and operation efficiency of the fund. Enterprises are the main consumer of resources and energy, as well as the main producer of environmental pollution. Due to the fact that environmental resources are public goods, and the long investment cycle and low efficiency of environmental protection, enterprises lack enthusiasm for investment. The government needs to resolve this problem through environment regulation. Researchers have found that the intensity of government's environmental regulation has

Manuscript received September 29, 2017; revised November 15, 2017 This work was supported in part by the Zhejiang Department of Science and Technology under Grant 2015C35038.

Yong Wang is with the School of Economics and Management, Southeast University, Nanjing, China (e-mail: 1318226182@qq.com).

Rongbing $\mathrm{Hu}$ was with Shanghai International Studies University, Shanghai, China. She is now with the Foreign Affairs Office, Zhejiang Business College, Hangzhou, 310053, China (e-mail: hurongbing8867@126.com). evident effect on enterprises behavior in investing environmental protection; the behavior affects the enterprise value through technological progress; and the investment efficiency affects the enterprise value though technological efficiency [1].

The government needs to explore effective ways to solve the external environmental problems, taking into account not only the rigid environmental regulation, but also long-term mechanism. An effective way is internalization of environmental cost, which means enterprises increase investment in environmental protection in order to reduce or even eliminate the pollution and damage caused during production and consuming processes. The purpose is to reduce and even eliminate pollution from the source by making enterprises to take upon themselves the cost of pollution, so as to attain a sustainable development. As the main cause of environmental pollution-enterprises only bear a small part of the environmental cost, a larger part of the cost is burdened by the public and the government. The environmental cost burdened by the main cause of pollution is obviously less than that burdened by the society. Therefore, enterprises should take responsibilities for this cost. The negative externality of environmental cost corresponds to the environmental management method of end treatment, but compared with source treatment, such as interception technology, clearer production technology, end treatment is more expensive and less effective and its rules to share environmental cost is not in conformity with the principle "whoever causes pollution is responsible for its treatment" [2].

\section{LITERATURE REVIEW OF BUSINESS MODEL OF ENVIRONMENTAL MANAGEMENT INDUSTRY}

A good business model is a primary condition for the success of an enterprise. The business model of an environmental protection enterprise refers to a series of factors and relations of the enterprise, which expound the business logic of the enterprise. Dongdong Yuan (2014) points out that China's environmental protection industry have undergone four phases: equipment manufacturing centered, engineering construction centered, investment operation centered, and integrated environment service provider. Divided by object, there are sewage treatment, solid waste treatment, and air contaminant treatment. China's sewage treatment enterprises have four main models: investment operation, water industry operation, water industry investment, and engineering, technology, and 
equipment provider. Solid waste treatment enterprises can be divided into government-led type, project investment operation type, and professional investment operation type. Air contaminant treatment enterprises mainly focus on the upstream links of desulfurization, denitration, raw material providing, and dust-cleaning apparatus, as well as downstream operation links. Driven by national policy, environmental protection industry has developed from one single industry chain to whole industry chain. The emergence of new business model will create integrated environment service providers and environment solution providers [3].

Chunyang Ji and Yaoping $\mathrm{Li}$ (2016) point out that "Internet +" environment has integrated into all aspects of social life. Internet technology can promote the integration of virtual economy and real economy, accelerate the interconnection of online and offline efforts, and a new business model driven by Internet technology has been formed, which greatly promote the generating of new mode of economic development. "Internet + environmental protection" means applying internet technology in environmental protection industry, building platform model, and improve the efficiency of environmental protection Internet service platform. Through case analysis, the authors believed that the development trend of environmental protection's $\mathrm{O} 2 \mathrm{O}$ business model is that the service platform will be professionalized and localized, the $\mathrm{O} 2 \mathrm{O}$ model will be applied more widely in industry; the development mode of "environmental protection + supply chain finance" will come into being; environmental protection $\mathrm{O} 2 \mathrm{O}$ service system will be generated based on mobile social networking platform [4].

An effective business model is the key to the success of an enterprise. "Customer value proposition, key resources, key processes, and profit model are four closely related factors, and can create and deliver value for the enterprises." Customer value proposition include the target customer, the work to be done, the things to be provide. Profit model consists of cost structure, profit model, earnings model, and the speed of the use of resource. Key resources include personnel, technology, product, equipment information, channel, partner, alliance, and brand. Key processes ensure the expandability and repeatability of the transfer mode of customer value proposition. A successful enterprise will combine these factors in a consistent and complementary way and form a stable system. The innovation of business model follows construction logic instead of analytic logic. An enterprise should seek market gap by standing on its own strategic position, de-structuring its eternal environment, and analyzing customer value. Then, it should integrate external resources to gradually construct its own capabilities, and promote the formation of new industrial system and new commercial model. Thirdly, innovation in business model should not be confined to existing business boundaries, but to expand them, striving to find new demands beyond the boundaries, and enlarge its benefit community by establishing interest and transaction relationships with other stakeholders, so as to build a business ecological system that center around itself. Business ecosystem in internet era emphasizes on value co-creation and competition and cooperation relationship, because the advantages of business model innovation mostly come from business ecosystem, and need the collaboration of upstream and downstream stakeholders. It is suggested that an enterprise should reform or even overset the existing value logic, build partly loop-locked value logic, build win-win value sharing links with stakeholders with the same vision, and finally build its competitive advantages based on business ecosystem [5].

Wei Chen (2015) takes a private gas company (Company A) as an example and studies its business model innovation. She believes that when an enterprise is designing its business model, it should analyze its own conditions and the external macroscopic environment. This is a process of coupling between external market opportunities and the enterprise's internal resources, and is also a process of constant trial and error. Her article analyzed the factors of the existing business model of Company A from four aspects: customer value proposition, profit model, key resources, and key processes, and found the main problems are: there is only one source of income, and the income may be unsustainable; the overall layout of the company's location needs optimization. The idea of building a new business model is suggested: increase income and reduce expenditure so as to improve management efficiency; accelerate the development of new gas source; increase downstream sales so as to steadily enlarge scale of operation; improve customer satisfaction, build good public image, and maximize shareholder value. She designed a new business model for Company A from the perspective of factor composing of business models. When implementing the new business model, the enterprise should unify its thinking, strengthen its culture construction, and improve cohesive force in enterprise; adjust business organization structure, motivate key staff from different aspects, and help them fully realize their own personal value; improve staff welfare, and improve their income. Before the implementation of the new business model, it should ensure the transient processes are in accordance with the laws and regulations. Currently the gas industry is supervised by the government from different methods such as new project approval, price approval, and gas source distribution, therefore investors cannot invest freely in this industry, creating actual barriers to entry. Besides, any business model cannot live without the financial support of the company. Company A needs to secure the initial fund of implementing the new business model, and comparatively strong economic strength of investing enterprises. Therefore, it should control cost, perfect risk control system, establish good relationships with a number of banks, actively sign gas contracts, and secure stable and long-term gas source [6].

Hualong Yu (2015) studies business model from the perspective of new energy cars. He points out that recent years China's new energy car industry has made great breakthrough, but there is still a big gap between China and other countries strong in new energy cars. New energy car industry has two paths of development: technology innovation-driven and business model innovation driven. Yu analyzes the business model of periodic lease of new energy cars. He analyzes the value chain of the business model of periodic lease, and builds a value network for the business model of periodic lease. By integrating the theoretical analysis of value network and the main components of 
business model, he comes up with an evaluation index system including six aspects. Finally he took Hangzhou's "mini bus" periodic lease business model as an evaluation object, and based on that, comes up with several suggestions of the development and operation of China's new energy car periodic lease business model [7].

Youqing Sun (2015) studies the business model of energy-saving services enterprises, discusses how to build its core competitiveness, and this has significant meaning for the development of energy conservation and environment protection industry. The article takes the strategic planning of enterprises operation and development of Nanjiang Sushang New Energy Technology Co. Ltd as an example, and by analyzing its business model, studies the construction of the enterprise key abilities, and comes up with strategies to build and perfect core competitiveness of the enterprise [8].

The main analytical thinking of the above literature is: first, define the connotations of business model by clarifying the key factors of business model, and using these factors' logic relationships to destructure business model. Then, take a specific industry or enterprise as an example, analyze the existing problems of its business model, and then propose solutions to these problems. When analyzing specific business model operation mode, dissect the new opportunities brought about to business model by Internet technology. Based on that, analyze the new business model and operation mechanism in the context of the Internet. Some researchers think that, against the background of the Internet, value chain is taken place by value network, and the realization of enterprise value is closely related to the value of the business ecosystem among stakeholders, as well as the value realization of the stakeholders.

\section{A RESEARCH ON THE BUSINESS MODEL OF ENVIRONMENTAL MANAGEMENT INDUSTRY FROM THE PERSPECTIVE OF STAKEHOLDERS}

"A business model is a conceptual tool that contains a series of factors and the relations between these factors", and is used to illuminate the business logic of value realization. The series of factors constitute the internal organization to provide customer value, including cooperative partner network, relational capital, etc. The purpose is to create sustainable, profitable income, and keep competitive edge. A representative business model concept is Wei Wei and Wuxiang Zhu (2011)'s definition. They believe that business model is the deal structure among stakeholders. Stakeholders include the staff, suppliers, partners, and customers, and the value exchange happened during their commercial activities form a value network. Alexander Osterwalder wrote in Business Model Generation that a business model contains nine factors: customer segmentation, value proposition, core resource, key business, channels, customer relations, key partnerships, cost structure, and source of revenue. These nine factors can be divided into four types: customer value, profit model, customer relations, and key resources capabilities. Wei and Zhu proposed the factors: orientation, operation system, key resources capabilities, profit model, cash flow structure, and value. In fact, some of the six factors have specific meaning, but some have abstract meaning. But there are inclusion relations between them. For example, profit model can include key resource capabilities, value can include cash flow structure. If further generalize, it can be concluded into four key factors: orientation, business structure, key resource capabilities, and value. Simply put, a business model is a mechanism to make money, whose money to make, how to make money, how to make money sustainably. Or we can say that value orientation, value production, and value distribution are the three aspects of general processes of a business model.

Enterprises' innovation in business models should focus on dynamic mechanism and feasible paths. Dynamic mechanism comes from internal or external. Internal source can be the pursuit of interest, the preference of entrepreneurs, or the needs of self-actualization. External source can be technological push, demand pull, and competition. The choice of paths mainly focuses on direction of innovation, degree of innovation, elements of innovation, and so on. An enterprise is a system that consists of different value activities. An innovation path means to optimize available resources, to improve element structure, in other words, to change the enterprise logic in value creation. Therefore business model innovation is to change the value creation logic [9].

For environmental protection enterprises, to analyze their business models also require analyzing the structure of deal between stakeholders. Stakeholders refer to "any individuals or groups who can affect the realization of an enterprise's goals, or can affect the process of the realization of an enterprise's goals." (Freeman, 1983) The stakeholders include consumers, shareholders, environmental groups, the public, government at all levels. But there are contradictions between the interest appeals of different interest bodies, as can be exemplified in how to deal environmental pollution. Enterprise pursue the maximization of its profit, and when they only focus on profit maximization, they will not be able to improve public welfare. From the perspective of game theory, environmental deterioration is a "tragedy of the commons". Since different stakeholders have different concern degrees and performance points on improving the environment, there will be a game between these stakeholders. And the environmental management measures finally adopted by the enterprises are in most cases a comprehensive result of the constant game between the stakeholders [2].

An enterprise is an economic entity of independent management and assumes sole responsibility for its profits or losses. Under national hypothesis, an enterprise will make decisions that benefit itself in pursuit of profit maximization. Government is the representative of public interest and a supervisor, and its goal is to pursue maximized public welfare. When enterprises and the government are faced with pollution problems, a certain enterprise might be reluctant to take measures, in fear that it would be the only one to invest in pollution treatment and the cost would not be recovered; some even refuse to take "pollution internalization" measures. The government, on the other hand, facing environmental pollution, especially a serious pollution, and under public pressure, would urgently seek solutions, or else its image would be damaged. It is clear that enterprises and the government have different goals, and thus different standpoints. The government only needs to protect the 
enthusiasm of enterprise investment, but also needs to create a fair competitive environment and safeguard public welfare. So there is a game between the government and enterprises. Considering that enterprises might try to escape the environmental cost that they should be responsible for, the government must supervise in order to improve the possibility for the enterprises to take pollution abatement measures. As for pollution treatment, there is also a game between governments of different regions and at different levels, for example, between central government and local government, or between governments of different regions. When the goals of central and local government are inconsistent, local governments, especially those from remote areas, would take advantage of this information asymmetry and "falsely execute" the policies set by the central government. In order to maximize public welfare while carrying out of environmental policies, we should change local governments' performance appraisal system which centered on economic interest, or even a simplified index system, and further improve supervision and information feedback. When two governments of the same level take part in an environmental pollution game, either of them is willing to do pollution control, which is called a game balanced strategy, and this requires the central government's intervention. Likewise, when enterprises are faced with the game of environmental pollution, their balanced strategy is also non-treatment. At this point, the government needs to interfere, formulate relevant policies, and try to achieve Pareto equilibrium.

Faced with environmental pollution and treatment, there is also a game between consumers and enterprises. The consumers' concern degree and sensitivity of environmental protection quality will in turn affect the choices of enterprises when they are making production decision. With the constant development and social progress, consumers' demand for quality life is growing, including the preference for a better environment. Enterprises are oriented by the need of consumers, and change their production function. We might as well divide consumer environmental sensitivity into three levels, high, medium, and low. The purchase behaviors of these three categories of consumers differ a lot, and will lead to the adopting of differentiated production policies by enterprises.

What role should the government play in dealing with environmental pollution? As early as 1990, Yining Li had pointed out that enterprises, residents, and the government (central government and local government) should share environmental management expenses. But what the government should bear is supplemental environmental management expenses, and the main part of it should be borne by the pollution subjects. The government shoulders more political, legal, administrative, and moral responsibilities. Therefore, when faced with environmental pollution and management, the government should introduce relevant polices without delay, increase institutional supply, give incentives to enterprises' environmental cost internalization, and promote internalization of environmental cost. To be specific, the policies are mainly about limitations on pollutant discharge of enterprises and supporting punitive measures, all of which will exert influence on the enterprises' operating decision. In this regard, the theoretical circle has three viewpoints: Pollution Heaven Hypothesis, Factor Endowment Hypothesis, and Porter Hypothesis. Pollution Heaven Hypothesis believes that if environmental regulation is strict, the cost of enterprises is bound to increase, and rational enterprise behavior will be inclined to choose to run business in a country or region that has low environmental compliance cost. Of course, comprehensive cost-effectiveness accounting needs to be made according to the advantages and disadvantages of a certain region. Factor Endowment Hypothesis believes that enterprises' enthusiasm in investment is dependent on the benefit brought by resource endowment advantages and the cost of compliance with environmental regulations. Porter Hypothesis believes that government regulation will promote enterprises' technological innovation, and thus improve enterprise competitiveness. We can see that these viewpoints are made from a comprehensive consideration of government institutional supply and enterprises' choice, and finally lie on the balance of comprehensive interest. In this regard, empirical results have shown that government regulation can effectively reduce environmental pollution density. Stakeholders have different appeal point for enterprises' environmental performance, therefore their influence on environmental management efficiency has been accepted by academic circles and practice circles.

Business model innovation is the deconstruction and remodeling of the core logic of value creation. Therefore, innovation in value chain links involves cooperation with upstream and downstream enterprises. Therefore, stakeholders should collaboratively improve connecting points, especially the key points of value chain links, which may contribute to increment of value, and even expand the value network beyond boundaries, and comprehensively consider environmental performance.

It is generally believed that business model is the logic of value creation. According to this, value proposition, value creation, and value distribution is the basic logic. The conceptual model designed below is based on this logical relationship. The proposition of environmental management industry depends on the balanced power of motivation and restriction. Motivation means that, if the government wants to encourage the development of a certain industry, or motivate enterprises to take investment measures to conduct pollution prevention and treatment, it may adopt fiscal and taxation policies to support enterprises, or compensate for their expenses, or give them other preferential policy. On the other hand, restriction means that, if enterprises do not take initiative in environment management, they will undertake the penalty of negative externality. Likewise, since stakeholders take part in value creation, they will naturally share the value. If there is no good mechanism to balance the interests of all parties, the business model must be short-lived. Therefore, faced with environmental management problem, there will be a comprehensive game between the stakeholders, and after that they will relocate environmental management, which will have two kinds of influence: the first is that importance will be attached to environmental management, which appears as the pressures put on core enterprises to make them take environmental management measures. The second influence is the impetus for environmental management. Taking good environmental management value 
proposition will win the recognition of consumers and stakeholders, and achieve good results, and this appears as incentive (see Fig. 1).

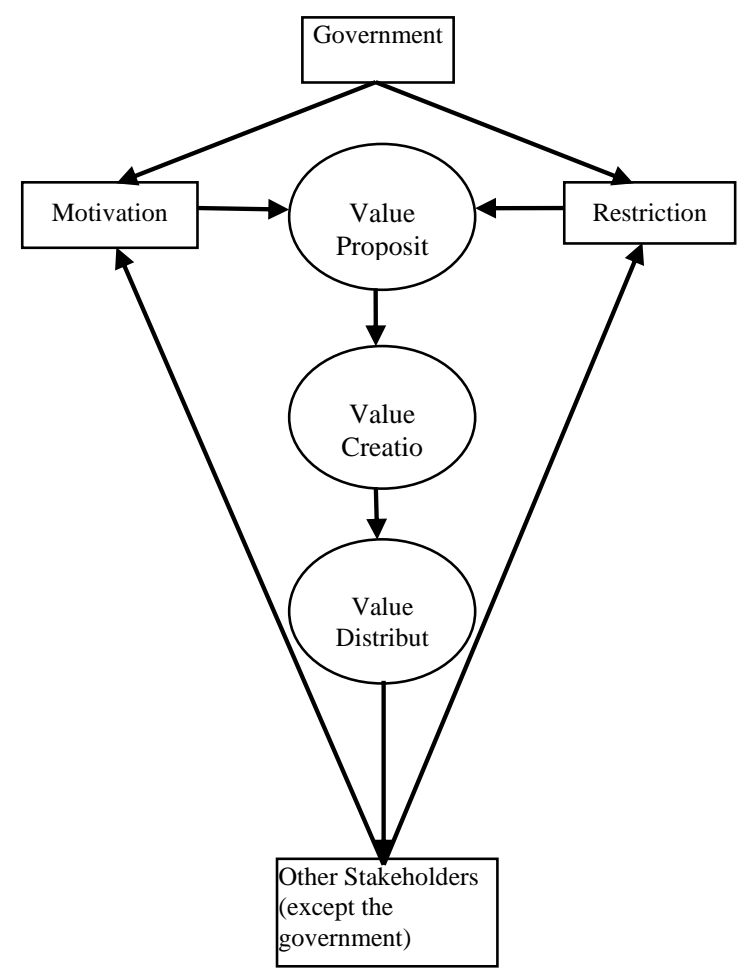

Fig. 1. Analysis graphics of the business model of environmental management industry from the perspective of stakeholders.

In this process, the government will play a role of motivation or restriction through environmental regulations, to guide and propel enterprises to take environmental protection behaviors. Stakeholders will give incentive to and put pressure on core enterprises to improve the environment, which appears as a mechanism combining incentive and restriction. These mechanisms will prove valid through constant practice, and be recognized and then solidify into a "rule relationship", and in turn become "institutional constraint" for enterprises and stakeholders, or even sublime into a "cultural self-consciousness", thus the business model of environmental management industry will have solid and sustainable cognitive basis. On the contrary, if core enterprises carry out technical improvement because of some trigger factor, it will increase the technical value. But if it cannot get the recognition and cooperation from other enterprises from the same value chain, it will face increase cost, which will result in the increase in product price. If consumers are insensitive to product's environmental-protective quality or indifferent to environmental changes, they would not buy these products of higher prices. Here, in the aggregation of the stakeholders of value chain, any factor, or any stakeholder's incoordination will break the balance. Therefore, these stakeholders will seek balance in the game of comprehensive interests including economic interest, social interest, and ecological interest, until the realization of Pareto Optimality. The constant game between stakeholders is also a process of interest redistribution. The overall trend of evolution should be constant improvement of both enterprises' economic benefit and environmental quality, and a collaborative development of environmental protection and economic development. See below for details.

\section{REFERENCES}

[1] Q. Chen, Environmental Regulation on Enterprises Environmental Investment and Enterprise Value, Beijing, $\mathrm{CN}$ : Economic Science Press, 2014, pp. 2-3.

[2] Q. Liu. "Supply chain environmental cost internal mechanism research," Ph.D. dissertation, Dept. Busi. Admin., Beijing Jiaotong Univ., Beijing, China, 2015.

[3] D.-D. Yuan, "China's environmental protection industry state quo and environmental enterprise business model," China Environmental Protection Industry, vol. 10, pp. 16-20, Oct. 2014.

[4] C.-Y. Ji and Y.-P. Li. "Environmental protection industry O2O business model exploration," Business Economy Research, vol. 23, pp. 196-197, Dec. 2016.

[5] X. Wang, D. Li, and X.-L. Zhang, "New technological marketization business model design - Based on construction and circumstances," Science and Technology Progress and Policy, vol. 15, pp. 1-8, Aug. 2013.

[6] W. Chen. "Private gas company a's business model innovation research," M.S. thesis, Dept. Busi. Admin., Southeast University, Nanjing, China, 2015.

[7] H.-L. Yu. "A research on periodic lease business model for China'S new energy cars based on value network," Ph.D. dissertation, Dept. Busi. Admin., Jiangsu University, Zhenjiang, China, 2015.

[8] Y.-Q. Sun, "Energy efficiency management enterprise key capability construction based on business model optimizing — Take Sushang new energy technology Co. Ltd as an example,” M.S. thesis, Dept. Busi. Admin., Southeast University, Nanjing, China, 2015.

[9] Q.-Z. Wang, A Research on Business Model in Internet Economy, Beijing, CN: Economic Science Press, 2015, pp. 1-2.

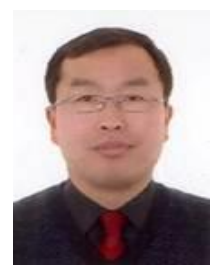

Yong Wang was born in Feb, 1969 in Anhui province, PRC. He obtained a bachelor's degree in science from Anhui Normal University in 1998, a postgraduate certificate in economics from Anhui Provincial Party School in 2000, and a master's degree in business administration from the University of Science and Technology of China in 2005. From 2009 to 2010, he studied in Zhejiang University as a visiting scholar with Professor Jin Xiangrong in economics. Now, he is a doctoral student of the School of Economy and Management of Southeast University.

He has been working with Zhejiang Business College in Hangzhou since 2003. He is Professor and the director of Campus Culture Construction Division. He has a number of works published, including Low-carbon City and City Brand (Chengdu, Sichuan: Southwest Jiaotong University Press, 2012), A Research on the Development Direction of Professional Incubator From the Perspective of Industrial Cluster (Chengdu, Sichuan: Southwest Jiaotong University Press, 2014), Marketing Theory an Practice (Chongqing: Chongqing University Press, 2011), etc. His current research interest is business model.

Prof. Wang is a member of Zhejiang Economic Society, and work as a researcher. He was awarded for his excellent work in China Professional Skills Comopetition.

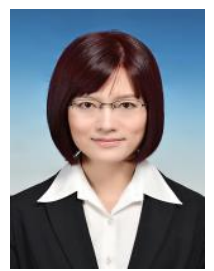

Rongbing Hu was born in June, 1988 in Zhejiang province, PRC. She obtained a bachelor's degree in English translation in 2010 from Tianjin Foreign Studies University in Tianjin, PRC, and a master's degree in English language and literature in 2013 from Shanghai International Studies University in Shanghai, PRC.

She has been working with Zhejiang Business in Hangzhou College since 2013. She is research assistant and foreign affairs secretary. She has a number of works published, including "A Research on the Problems and Solutions of English Language Teaching in Sino-Foreign Joint Educational Program in Vocational Colleges"(2016), "A Research on the Paths to Improve the Quality of Sino-Foreign Joint Educational Program in Vocational Colleges" (2016), "A Study on International Talents Cultivation in Higher Vocational Education in the Context of 'Belt and Road' Initiative" (2017), etc. Her current research interest is education internationalization.

$\mathrm{Ms}$. $\mathrm{Hu}$ was awarded as "Anual Advanced Individual" by Zhejiang Education International Exchange Association Higher Vocational Branch for several consecutive years from 2013 to 2016. 